\title{
Selective estrogen receptor modulator with estrogen does not affect the proliferation and apoptosis of uterine leiomyoma cells
}

\author{
Shu-Lan Lv ${ }^{1 \#}$, Rui Wang ${ }^{2 \#}$, Xue Xue ${ }^{1 \#}$, Lan-Bo Zhao ${ }^{3}$, Xiao-Qian Tuo ${ }^{1}$, Si-Jia Ma ${ }^{1}$, Dong-Xin Liang ${ }^{1}$, \\ Yi-Ran Wang ${ }^{1}$, Xue Feng ${ }^{1}$, Qing Li ${ }^{1}$, Qi Wang ${ }^{1}$, Lu Han ${ }^{1}$, Qi-Ling Li ${ }^{1}$ \\ ${ }^{1}$ Department of Obstetrics and Gynecology, Xi'an Jiaotong University, Xi'an, China; ${ }^{2}$ ART Center, Northwest Women's and Children's Hospital, \\ Xi'an, Shaanxi, China; ${ }^{3}$ Guipei 77, Health Science Center, Xi'an Jiaotong University, Xi'an, China \\ Contributions: (I) Conception and design: QL Li, SL Lv, R Wang, X Xue; (II) Administrative support: Xi'an Jiaotong University; (III) Provision of \\ study materials or patients: LB Zhao, XQ Tuo, SJ Ma; (IV) Collection and assembly of data: DX Liang, YR Wang, X Feng; (V) Data analysis and \\ interpretation: Q Li, Q Wang, L Han; (IV) Manuscript writing: all authors; (VII) Final approval of manuscript: all authors. \\ \#These authors contributed equally to this work. \\ Correspondence to: Qi-Ling Li. Department of Obstetrics and Gynecology, Xi'an Jiaotong University, 277 Yanta West Road, Xi'an, Shaanxi, China. \\ Email: liqiling@mail.xjtu.edu.cn.
}

\begin{abstract}
Background: The administration of menopausal hormone therapy (MHT) in women with uterine leiomyomas is still debated. The purpose of this article is to study the proliferation and apoptosis of uterine leiomyoma cells under the impact of selective estrogen receptor modulator (SERM) combined with estrogen. Methods: Primary cultured uterine leiomyoma cells in the perimenopausal period were treated with estrogen (17-beta estradiol) + SERM (raloxifene) as the tissue selective estrogen complex (TSEC) group, while both estrogen + medroxyprogesterone acetate $(\mathrm{E}+\mathrm{P})$ and estrogen $(\mathrm{E})$ alone as were used as control groups. The expression of proliferating cell nuclear antigen (PCNA) and B-cell lymphoma-2 (Bcl-2) proteins was assessed by methylthiazolyldiphenyl-tetrazolium bromide (MTT) assay and western-blot analysis, respectively.
\end{abstract}

Results: The proliferation in the TSEC group was weaker than the control groups $(\mathrm{P}<0.001)$. There was no statistical difference between the TSEC and blank control group on cell proliferation at $72 \mathrm{~h}(\mathrm{P}=0.13)$. However, there was a significant difference between the other groups $(\mathrm{P}<0.001)$. PCNA expression of TSEC was lower than that of the $\mathrm{E}+\mathrm{P}$ and $\mathrm{E}$ groups $(\mathrm{P}<0.05)$. There was no statistical difference in the expression of PCNA between the TSEC and blank control groups $(\mathrm{P}=0.63)$. Bcl-2 expression of TSEC was lower than that of the $\mathrm{E}+\mathrm{P}$ and $\mathrm{E}$ groups $(\mathrm{P}<0.05)$. There was no statistical difference in the expression of $\mathrm{Bcl}-2$ between the TSEC group and the blank control group $(\mathrm{P}=0.60)$.

Conclusions: SERM combined with estrogen may have a better safety for perimenopausal women with uterine leiomyoma in MHT.

Keywords: Menopausal hormone therapy (MHT); tissue selective estrogen complex (TSEC); leiomyoma

Submitted Dec 30, 2019. Accepted for publication Jul 14, 2020.

doi: $10.21037 /$ tcr-19-3022a

View this article at: http://dx.doi.org/10.21037/tcr-19-3022a

\section{Introduction}

The morbidity of uterine leiomyomas is more than $70 \%$, and $62 \%$ of women will enter menopause with leiomyomas $(1,2)$. The treatment of uterine leiomyomas depends on the size, quantity, clinical symptoms, fertility requirements, and patients' subjective wishes. Myomectomy or hysterectomy is the most commonly used method of traditional treatment, but for women who require conservative treatment or fertility requirements, the pursuit of the best treatment options is particularly important. At present, non-traditional surgical treatments, such as gonadotropin- 
releasing hormone $(\mathrm{GnRH})$ agonists/antagonists, selective progesterone receptor regulators, levonorgestrelreleasing intrauterine system (LNG-IUS), uterine artery embolization, and high-intensity focused ultrasound (HIFU), provide new treatment options for conservative treatment of uterine leiomyoma from different perspectives (3). The principle of treatment for perimenopausal women with uterine leiomyoma is the same as above, but when they are treated with menopausal hormone therapy (MHT), leiomyoma is an aspect to be considered in drug evaluation. The numerous acknowledged benefits of MHT have been widely recognized in the treatment of many immediate and delayed postmenopausal changes (4-6). MHT methods include estrogen alone, progesterone alone, and a combination of estrogen and progesterone. However, the administration of MHT in women with uterine leiomyomas is still debated (7-10). Some researchers have proposed that estroprogestin therapy could increase the incidence of uterine leiomyomas and produce a proliferative stimulus by increasing volume (11). Therefore, MHT is used cautiously in women with uterine leiomyomas, which influence the implementation of MHT and increase the follow-up times.

The issues posed above were considered in the development of a new, innovative, combination treatment, which replaces progesterone with selective estrogen receptor modulator (SERM) (12). SERMs are estrogen receptor (ER) ligands that display an unusual tissueselective pharmacology. That is, they are antagonists in the breast, agonists in the bone, liver, and cardiovascular system, and mixed agonists/antagonists in the uterus (13). In 2010, Bolognese first proposed that SERMs are compatible with estrogen, which might be more beneficial to the effectiveness and safety of MHT (14). A new dosage form of hormone drugs emerged, which was a combination of estrogen and SERMs, called tissue-selective estrogen complexes (TSECs). Compared with the traditional MHT method combined with estrogen and progestin, it can reduce menopausal syndrome and has a good safety in the breasts, ovaries, cardiovascular system, and venous thrombosis (15-17). However, for leiomyomas, TSEC still requires further study.

Raloxifene, a benzothiophene derivative, is the most widely studied of the SERMs. Most of the studies found a benefit profile with association of raloxifene and estrogen on women's quality of life, satisfaction with the treatment, and vaginal dryness (18). Some studies have shown that the use of raloxifene combined with low-dose estrogen produced no increase in endometrial thickness (19-21).
Some studies have shown an increased endometrial thickness after 3 months of treatment. The mean values reported, however, did not exceed $5 \mathrm{~mm}$, and most of the biopsy results revealed benign endometrial proliferation $(22,23)$. Some studies suggest that raloxifene does not increase the volume of leiomyoma, and some believe that raloxifene does not promote the proliferation of leiomyoma cells, but others believe that the effect of raloxifene on leiomyoma is dose-dependent (24-28). As an MHT method, the safety of TSEC has gained the most attention for those with leiomyomas. However, the effect of SERMs combined with estrogen on the proliferation and apoptosis of cultured leiomyoma cells has not been reported.

In this study, we used raloxifene combined with 17beta estradiol and compared it with traditional estrogen combined with progesterone and estrogen alone to observe the effects of different MHT methods on the proliferation and apoptosis of cultured leiomyoma cells in vitro.

\section{Methods}

\section{Hematoxylin and eosin (HE) staining}

Leiomyoma tissues were obtained from 40-50-year-old patients undergoing hysterectomy due to myoma, with the patient's permission and signed informed consent before operation, who had received no hormonal therapy for at least six menstrual cycles before surgery. The study was conducted in accordance with the Declaration of Helsinki (as revised in 2013). The study was approved by the Ethics Committee of the First Affiliated Hospital of Xi'an Jiaotong University (No. XJTU1AF2016LSK-14: the registration number of ethics board). This was an in vitro study, and part of the tissues was used for cell culture, while the other part was fixed in neutral formalin, dehydrated, then clarified, embedded in paraffin, sectioned at 5- $\mu \mathrm{m}$ thicknesses, and stained with HE (Shanghai Jianglai Biotechnology Co., Ltd. DH0052) for observation of general histology.

\section{Immunobistochemistry}

After dewaxing, the slides were blocked with $10 \%$ normal goat serum (Gibco Life Technologies, USA) for 30 minutes before being incubated with primary antibodies at room temperature. These primary antibodies were incubated overnight at $4{ }^{\circ} \mathrm{C}$ : alpha smooth muscle actin ( $\alpha$-Actin, 1:1,000, Abcam Cat\# ab69512, RRID:AB_2222725) antibody and estrogen receptor alpha (ER- $\alpha, 1: 1,000$, 
Abcam Cat\# ab3743, RRID:AB_304042) antibody. Goat anti-rabbit secondary antibody (1:7,000, Abcam Cat\# ab6721, RRID:AB_955447) was incubated for $1 \mathrm{~h}$ at room temperature. Then, the slides were colored using a $\mathrm{DAB}$ (3,3'-diaminobenzidine) Kit (ZLI-9017, ZSGB-BIO, China) according to the manufacturer's instructions. Images were acquired using Olympus BX51 confocal microscopes.

\section{Primary culture of uterine leiomyoma cells}

Leiomyoma tissues were digested and immediately transferred into phosphate-buffered saline (PBS: $\mathrm{NaCl}$ $8 \mathrm{~g}, \mathrm{KH}_{2} \mathrm{PO}_{4} 0.20 \mathrm{~g}, \mathrm{Na}_{2} \mathrm{HPO}_{4} \cdot 12 \mathrm{H}_{2} \mathrm{O} 3.49 \mathrm{~g}, \mathrm{KCl} 0.20 \mathrm{~g}$, double steamed water $1,000 \mathrm{~mL}, \mathrm{pH} 7.2-7.4)$ containing $100 \mathrm{U} / \mathrm{mL}$ of penicillin (Thermo Fisher Scientific, Inc., USA) and $100 \mu \mathrm{g} / \mathrm{mL}$ of streptomycin (Thermo Fisher Scientific, Inc., USA). Ophthalmic scissors were used to cut the samples into approximately $1-3 \mathrm{~mm}^{3}$ pieces. These pieces were digested with $0.1 \%$ collagenase (SigmaAldrich, USA) at $37^{\circ} \mathrm{C}$ for $4 \mathrm{~h}$. Dulbecco's Modified Eagle Medium (DMEM; Thermo Fisher Scientific, Inc., USA) supplemented with 10\% bovine serum albumin (Gibco Life Technologies, USA) was used to terminate the digestions. After digestion, the cells were washed three times with PBS, and dispersed cells were collected. The cell density was adjusted to $1-5 \times 10^{4}$ cells $/ \mathrm{mL}$, then seeded in a $25-\mathrm{mL}$ cell culture flask and incubated at $37^{\circ} \mathrm{C}$ in a cell culture (Nuaire NU-5800, USA) incubator with $5 \% \mathrm{CO}_{2}$ and saturated humidity. When the cells had adhered, the medium was replaced at 24-48 h. When a confluent monolayer of cells appeared, the cells were digested with $0.25 \mathrm{mg} / \mathrm{mL}$ trypsin (Gibco Life Technologies, USA) for subculture. All cells were free of bacterial, yeast, fungal, and mycoplasma contaminations.

\section{Cellular immunocytochemistry}

When cells adhered to $50-60 \%$, the culture was terminated. Cells were fixed in $4 \%$ paraformaldehyde for $30 \mathrm{~min}$ and permeabilized with Triton X-100 (0.3\%, ZSGB-BIO, China) for $10 \mathrm{~min}$. Uterine leiomyoma cells were suspended in 10\% normal goat serum (Gibco Life Technologies, USA) and then incubated with primary ER-a antibody (1:1,000, Abcam Cat\# ab3743, RRID:AB_304042) overnight at $4{ }^{\circ} \mathrm{C}$. Then, cells were washed and incubated in the secondary antibody $(1: 7,000$, Abcam Cat\# ab6721, RRID:AB_955447) for $1 \mathrm{~h}$ at room temperature. Uterine leiomyoma cells were applied in
DAB Kit (ZLI-9017, ZSGB-BIO, China) following the manufacturer's protocol. When the chromogenic process was completed, we took a photograph under the microscope and made a statistical analysis.

\section{Cellular immunofluorescence}

Cells were seeded in 6-well plates and maintained for $48 \mathrm{~h}$. After being washed 3 times with PBS, cells were fixed in $4 \%$ paraformaldehyde solution for $30 \mathrm{~min}$, permeabilized with $0.3 \%$ Triton $\mathrm{X}-100$ for $10 \mathrm{~min}$, and suspended in $10 \%$ normal goat serum (Gibco Life Technologies, USA) for $10 \mathrm{~min}$, then incubated with the primary antibodies: $\alpha$-Actin (1:1,000, Abcam Cat\# ab69512, RRID:AB_2222725), ER- $\alpha$ (1:1,000, Abcam Cat\# ab3743, RRID:AB_304042), and ER- $\beta$ (1:1,000, Abcam Cat\# ab3576, RRID:AB_303922) overnight at $4{ }^{\circ} \mathrm{C}$. After another three washes with PBS, the cells were incubated with secondary antibody for $1 \mathrm{~h}$ at room temperature. DAPI (4',6-diamidino-2-phenylindole) reagent (Shanghai Leuven Biotechnology Co., Ltd., China) was used to counterstain the nuclei. The result of the staining was observed with an inverted fluorescence microscope system (OLYMPUS, X53, Olympus Corporation, Japan).

\section{Study design}

This study was divided into four groups according to different combinations of drugs: $10^{-7} \mathrm{M} 17$-beta estradiol (Abbott Healthcare Products B.V.) $+10^{-9} \mathrm{M}$ raloxifene (Dalian Mei Lun Biotechnology Co., Ltd.) as the TSEC group, $10^{-7} \mathrm{M} 17$-beta estradiol $+3.3 \times 10^{-8} \mathrm{M}$ medroxyprogesterone acetate (Beijing Yimin Pharmaceutical Co., Ltd.) as the $\mathrm{E}+\mathrm{P}$ group, $10^{-7} \mathrm{M} 17$-beta estradiol alone as the $\mathrm{E}$ group, and a control group $(13,29,30)$. After different treatment, the proliferation and apoptosis of primary cultured uterine leiomyoma cells were analyzed by methylthiazolyldiphenyltetrazolium bromide (MTT) and western blot.

\section{MTT assay}

Cell viability was assessed using an MTT assay (Sigma, USA). Uterine leiomyoma cells were seeded into 96 well plates and incubated for 24,48 , and $72 \mathrm{~h}$ in culture media, respectively. A total of $20 \mu \mathrm{L}$ of MTT $(5 \mathrm{mg} / \mathrm{mL})$ was then added to each well, the cells were incubated for a further $4 \mathrm{~h}$ at $37^{\circ} \mathrm{C}$, and $150 \mu \mathrm{L}$ of dimethyl sulfoxide (DMSO, Thermo Fisher Scientific, Inc., USA) was added to each 

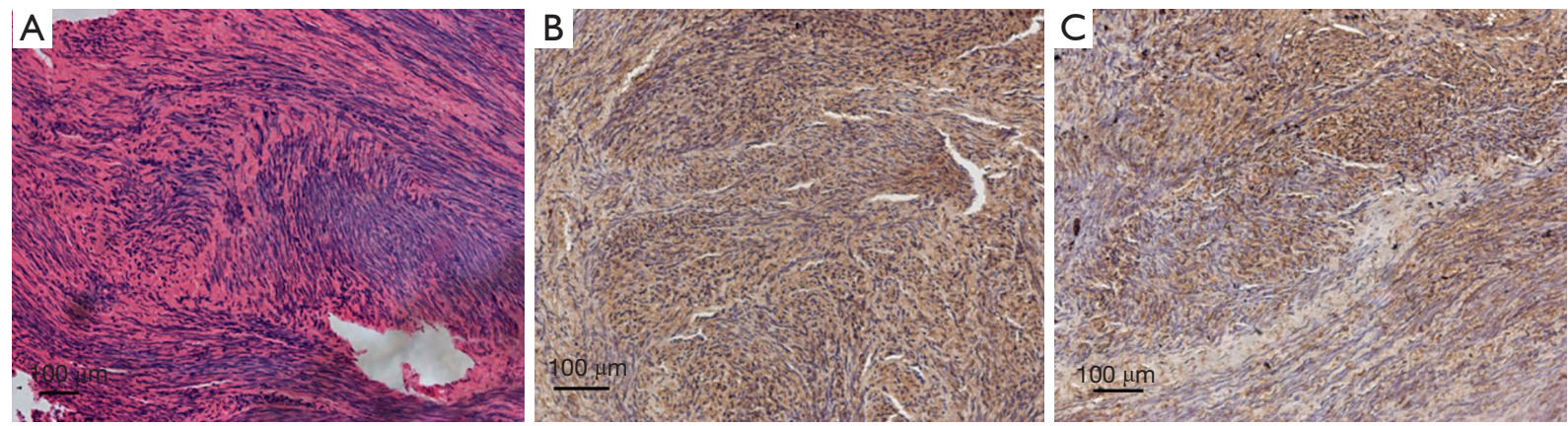

Figure 1 Histological identification of uterine leiomyoma. (A) HE staining of uterine leiomyoma (50x). (B) Alpha-Actin staining of uterine leiomyoma (50x). (C) ER staining of uterine leiomyoma (50x).

well and incubated at $37^{\circ} \mathrm{C}$ for $20 \mathrm{~min}$. The optical density (OD) was measured at $490 \mathrm{~nm}$.

\section{Western blot}

Western-blot was used to evaluate the expression of PCNA and Bcl-2 proteins in all groups. Total protein was isolated using radioimmunoprecipitation assay (RIPA) lysis buffer (Beijing Solarbio Science and Technology Co., LTD., China) supplemented with protease inhibitor cocktail (Hangzhou Reagent Company, China) on ice, and the concentration of the protein was detected using a BCA protein assay kit (Xi'an Heart Biotech Corp., China) according to the manufacturer's instructions. Gel preparation referenced the sodium dodecyl sulfate polyacrylamide gel electrophoresis (SDS-PAGE) kit (Xi'an Heart Biotech Corp., China) manufacturer's instructions. Protein samples were handled with SDSPAGE gel electrophoresis and transferred to polyvinylidene difluoride (PVDF) membranes (Millipore, USA). PVDF membranes were incubated with these primary antibodies overnight: proliferating cell nuclear antigen (PCNA, 1:1,000, Abcam Cat\# ab18197, RRID:AB_444313) monoclonal antibody, B-cell lymphoma-2 (Bcl-2, 1:1,000, Abcam Cat\# ab79204, RRID:AB_1603636) monoclonal antibody and beta-actin (1:2,000, Bioss Cat\# bs-0061R, RRID:AB_10855480). Then, the PVDF membranes were incubated with goat anti-rabbit secondary antibody $(1: 7,000$, Abcam Cat\# ab6721, RRID:AB_955447) for $2 \mathrm{~h}$ at room temperature. After another three washes, the proteins bound with the antibodies were visualized with an enhanced electrochemiluminescence (ECL) system (BIO-RAD GelDoc 2000, USA).

\section{Statistical analysis}

Each experiment was performed more than three times, and the results were analyzed using SPSS software version 18.0 (SPSS, Inc., Chicago, IL, USA). The statistical methods were general linear one-way ANOVA. $\mathrm{P}<0.05$ had statistical significance.

\section{Results}

\section{Histological identification of uterine leiomyoma}

The uterine leiomyoma tissue slides were stained with HE, and results showed spindle smooth muscle cells under a microscope (Figure 1A). Immunohistochemical staining showed that the expression of alpha-actin (Figure $1 B$ ) and ER (Figure 1C) was positive in uterine leiomyoma cells.

\section{Cell identification of uterine leiomyoma}

Primary cultured uterine leiomyoma cells showed spindle shape after adherence (Figure $2 A, B, C, D$ ). Alpha-actin was highly expressed in exercise cells of eukaryotes, and the expression in the cytoplasm was more than that in the cytoskeleton. Alpha-actin was highly expressed in the cytoplasm of uterine leiomyoma cells (Figure 2E). Immunocytochemical staining with anti-alpha-actin monoclonal antibody showed that the cells had a brownyellow filamentous structure in the cytoplasm, which was the location of actin and confirmed to be smooth muscle cells (Figure $2 F$ ). The positive cells were actin-expressing cells. The positive cells/total cells were the positive rate, and it was $94 \% \pm 2.5 \%$. The expression of ER-alpha in leiomyoma cells was in the cytoplasm. Immunofluorescence 

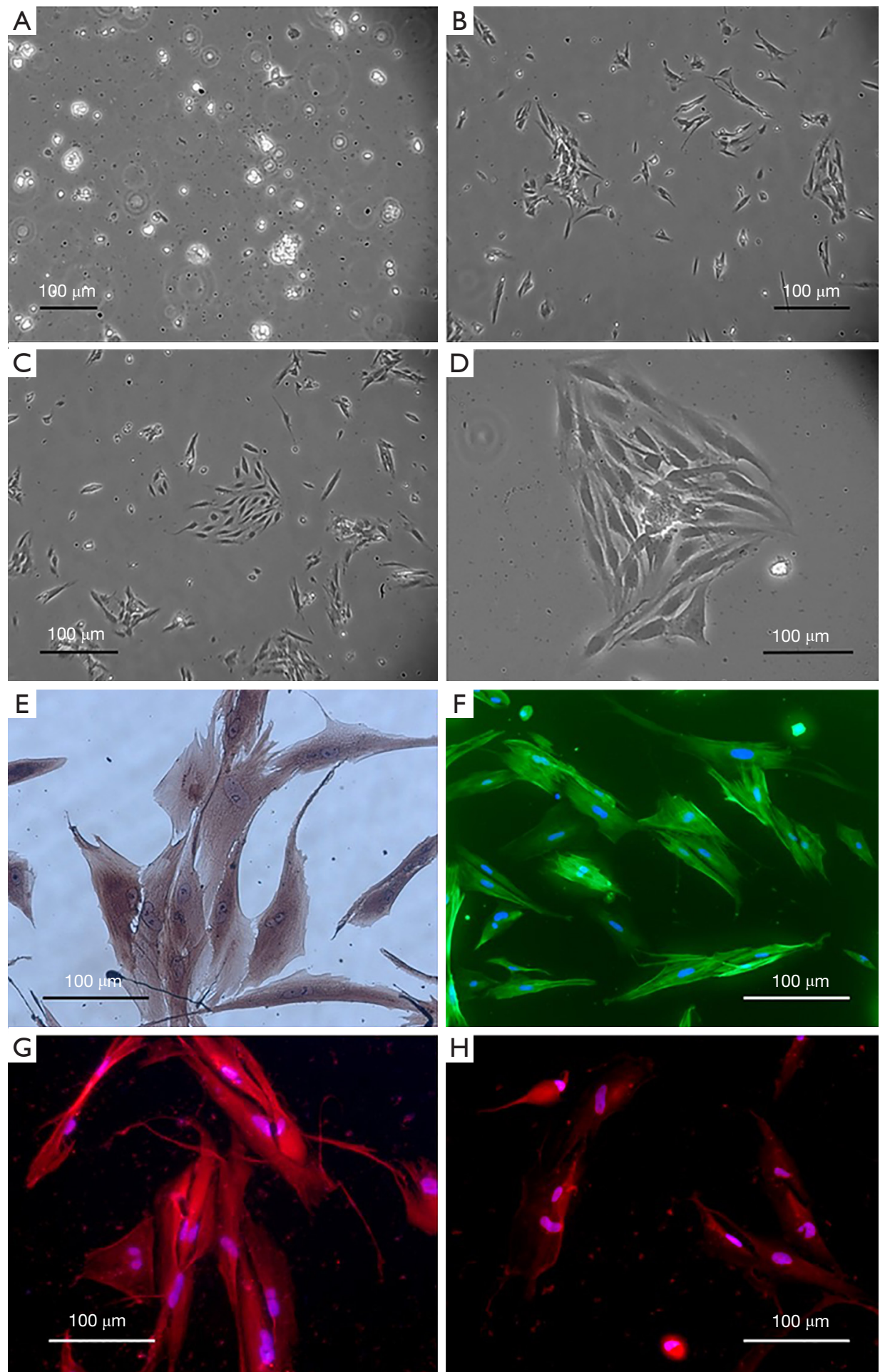

Figure 2 Cell identification of uterine leiomyoma. (A) Adherence of leiomyoma cells after 24 h culture (100x). (B) Leiomyoma cells were cultured to $48 \mathrm{~h}(100 \times)$. (C) Leiomyoma cells were cultured to $72 \mathrm{~h}(100 \times)$. (D) Leiomyoma cells protruded longer and contacted each other (200x). (E) Alpha-Actin staining of uterine leiomyoma cells (200x). (F) Immunofluorescence staining of alpha-Actin in uterine leiomyoma cells $(200 \times)$. (G) Immunofluorescence staining of ER-alpha in uterine leiomyoma cells $(200 \times)$. (H) Immunofluorescence staining of ER-beta in uterine leiomyoma cells $(200 x)$. 
Table 1 Methylthiazolyldiphenyl-tetrazolium bromide (MTT) results of TSEC, E+P, E and blank control

\begin{tabular}{lccc}
\hline \multirow{2}{*}{ Groups } & \multicolumn{3}{c}{ OD mean value } \\
\cline { 2 - 4 } & $24 \mathrm{~h}$ & $48 \mathrm{~h}$ & $72 \mathrm{~h}$ \\
\hline TSEC & $0.218 \pm 0.013$ & $0.326 \pm 0.009$ & $0.409 \pm 0.015$ \\
E+P & $0.395 \pm 0.016$ & $0.489 \pm 0.019$ & $0.596 \pm 0.012$ \\
E & $0.289 \pm 0.012$ & $0.398 \pm 0.013$ & $0.499 \pm 0.011$ \\
Blank control & $0.201 \pm 0.011$ & $0.299 \pm 0.018$ & $0.393 \pm 0.021$ \\
Serum control & $0.056 \pm 0.002$ & $0.109 \pm 0.006$ & $0.117 \pm 0.006$ \\
\hline
\end{tabular}

TSEC group: estrogen (17-beta estradiol) + SERM (raloxifene), E+P group: estrogen (17-beta estradiol) + medroxyprogesterone acetate, E group: estrogen (17-beta estradiol) alone.

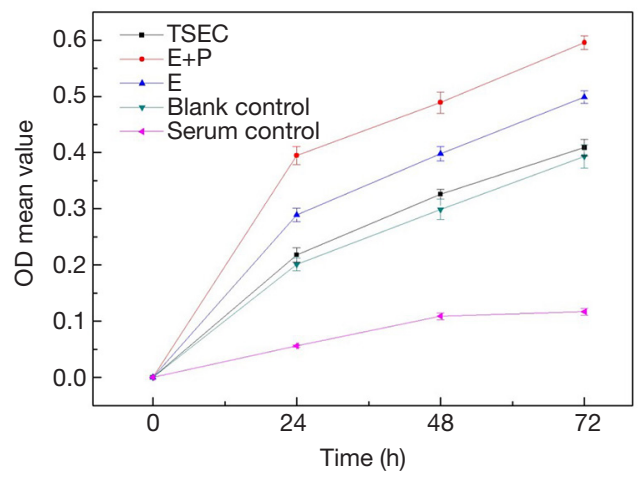

Figure 3 OD values of different groups in MTT assay. TSEC, $\mathrm{E}+\mathrm{P}, \mathrm{E}$ and blank control groups were cultured for 24,48 and $72 \mathrm{~h}$ respectively, OD mean values of each group were displayed. TSEC group: estrogen (17-beta estradiol) + SERM (raloxifene), E+P group: estrogen (17-beta estradiol) + medroxyprogesterone acetate, E group: estrogen (17-beta estradiol) alone.

staining with ER-alpha polyclonal antibody showed red fluorescence in the cytoplasm, indicating that ER- alpha was positive in these cells (Figure 2G). The expression of ERbeta in leiomyoma cells was localized in the cell membrane. Immunofluorescence staining of primary cultured cells with ER-beta polyclonal antibody showed red fluorescence on the cell membrane, indicating that ER-beta was positive in the primary cultured cells (Figure $2 H$ ).

\section{Effect of TSEC on the proliferation of uterine leiomyoma cells}

TSEC, E+P, E, and blank control groups were cultured for 24,48 , and $72 \mathrm{~h}$ respectively, and the OD was measured separately (Table 1). Results showed that: (I) there was a significant difference at $24 \mathrm{~h}$ between the TSEC and control groups $(\mathrm{P}=0.022)$. With this exception, there was a significant difference between the other groups $(\mathrm{P}<0.001)$. (II) There was a significant difference at $48 \mathrm{~h}$ between the TSEC and control groups $(\mathrm{P}=0.014)$. With this exception, there was a significant difference between the other groups $(\mathrm{P}<0.001)$. (III) There was no significant difference at $72 \mathrm{~h}$ between the TSEC and control groups $(\mathrm{P}=0.13)$. However, there was a significant difference between the other groups $(\mathrm{P}<0.001)$ (Figure 3). (IV) Western blot analysis of PCNA (molecular weight $30 \mathrm{kD}$ ) and internal reference beta-actin (molecular weight $43 \mathrm{kD}$ ) proteins are shown in Figure $4 A$. Repeated tests were conducted on three occasions, showing identical results. The expression of PCNA protein in the TSEC group was lower than that in the $\mathrm{E}+\mathrm{P}(1.04 \pm 0.03 v s$. $1.23 \pm 0.04)$ and $\mathrm{E}(1.04 \pm 0.03$ vs. $1.15 \pm 0.01)$ groups, and the differences were statistically significant $(\mathrm{P}<0.05)$. However, there was no significant difference in the expression of PCNA between TSEC and blank control groups $(1.04 \pm 0.03$ vs. $1.02+0.05, \mathrm{P}=0.63$ ) (Figure $4 B$ ).

\section{Effect of TSEC on apoptosis of uterine leiomyoma cells}

Western blot analysis of Bcl-2 (molecular weight $26 \mathrm{kD}$ ) and internal reference beta-actin (molecular weight $43 \mathrm{kD}$ ) is shown in Figure 4C. Repeated tests were conducted on three occasions, showing identical results. The expression of $\mathrm{Bcl}-2$ protein in TSEC was lower than that in the $\mathrm{E}+\mathrm{P}$ $(0.63 \pm 0.04$ vs. $1.17 \pm 0.01)$ and $\mathrm{E}(0.63 \pm 0.04 v s .1 .04 \pm 0.02)$ groups, and the differences were statistically significant $(\mathrm{P}<0.05)$. However, there was no significant difference between the TSEC and blank control groups $(0.63 \pm 0.04 v s$. 


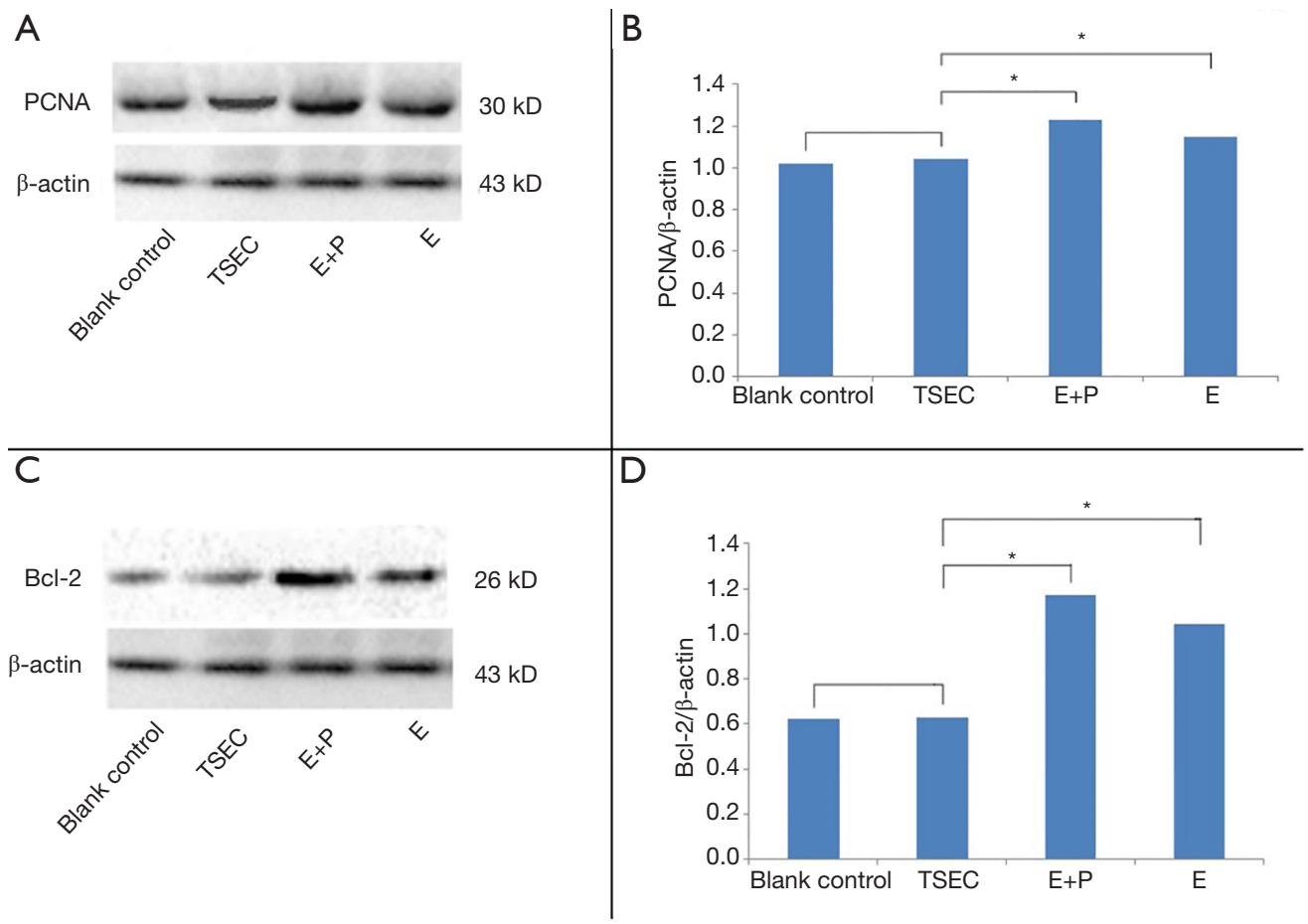

Figure 4 The effect of SERM combined with estrogen on the proliferation and apoptosis of uterine leiomyoma cells. (A) Results of PCNA protein band development through Western-Blot. (B) Contrast of PCNA protein gray value. (C) Results of Bcl-2 protein band development through Western-Blot. (D) Contrast of Bcl-2 protein gray value. TSEC group: estrogen (17-beta estradiol) + SERM (raloxifene), E+P group: estrogen (17-beta estradiol) + medroxyprogesterone acetate, E group: estrogen (17-beta estradiol) alone. *, stands for $\mathrm{P}<0.05$, and the difference was statistically significant.

$0.62 \pm 0.01)(\mathrm{P}=0.60)$ (Figure $4 D)$.

\section{Discussion}

Bolognese et al. first proposed a combination of SERMs and estrogen in 2010, which was considered to be more beneficial to the effectiveness and safety of MHT (14). Compared with traditional estrogen and progesterone, TSEC replaces progesterone components with SERMs, avoiding the risk of breast cancer caused by progesterone and maintaining the beneficial effects of estrogen. At the same time, SERMs have the characteristic of tissueselective expression (31). These features enable SERMs to alleviate menopausal syndrome (such as hot flashes) and prevent bone loss in menopausal women, while having good safety for breast, endometrium, ovary, cardiovascular and other aspects. The effect of SERMs on the volume of uterine leiomyoma has been studied extensively $(2,24,32)$. These data showed that SERMs can inhibit the growth of leiomyoma and even reduce the volume by regulating the proliferation and apoptosis of leiomyoma cells. The randomized controlled trial (RCT) results of Jirecek et al. showed that SERMs reduced the size of fibroids in 25 perimenopausal women over a three-month period compared with the control group. Palomba et al.'s clinical trial showed that SERMs had no significant effect on the volume growth of uterine myometrium and leiomyoma, and there was no significant difference between SERMs and the control group. It should be considered whether TSEC, a complex formed by SERMs with one or more estrogens, as compared with SERMs alone, has the same biological effects on leiomyoma. In this study, we used raloxifene $\left(10^{-9} \mathrm{M}\right)$ combined with 17 -beta estradiol $\left(10^{-7} \mathrm{M}\right)$. Clinical trials have shown that when the serum concentration of raloxifene was $10^{-9} \mathrm{M}$, the oral dose fluctuated approximately $30-150 \mathrm{mg} / \mathrm{d}$ (33). Another study used $10^{-9} \mathrm{M}$ to calculate the oral dose of $180 \mathrm{mg} / \mathrm{d}$ (34). Liu et al. showed that low concentration $\left(10^{-9} \mathrm{M}\right)$ of raloxifene might inhibit the growth of leiomyoma cells, whereas high concentrations $\left(10^{-8} \mathrm{M}, 10^{-7} \mathrm{M}\right)$ of raloxifene might promote their 
growth (13). In the three groups treated with drugs, 17-beta estradiol was all $10^{-7} \mathrm{M}(13)$.

Uterine leiomyoma is an estrogen-dependent tumor. The high expression of estrogen receptor in uterine leiomyoma is one of its pathological mechanisms. In our study, the proliferation ability of TSEC was lower than that of the $\mathrm{E}+\mathrm{P}$ and $\mathrm{E}$ groups. However, there was no significant difference between the blank control group, suggesting that SERM combined with estrogen might not promote the proliferation of leiomyoma, but not completely inhibit estrogen. The mechanism may be related to the effect of SERMs on leiomyoma: studies have confirmed that SERMs do not promote growth or reduce the volume of perimenopausal uterine leiomyoma by reducing estrogen level $(24,32,35)$. SERMs can express estrogen receptor inhibitor in leiomyoma cells. In this research, the TSEC group used SERM and estrogen at the same time, but the added estrogen dose cannot play the role of proliferation in uterine myoma cells. So, this combination can not only inhibit the proliferation of myoma cells, but also achieve the effect of MHT. At the same time, leiomyoma cells in the $\mathrm{E}+\mathrm{P}$ group proliferated actively, with the exception that estrogen promoted the growth of cells, and progesterone also played an important role. Progesterone can promote mitosis and stimulate the growth of leiomyoma (36). The results of clinical studies showed that compared with oral MHT, the use of estrogen and oral progesterone was more likely to increase the volume of leiomyoma (8). The results of this research show that TSEC may have better safety than $\mathrm{E}+\mathrm{P}$ in the selection of MHT for perimenopausal uterine leiomyoma patients. In addition, the leiomyoma cells treated by estrogen alone showed active proliferation, while the leiomyoma cells treated by SERMs and estrogen together did not have the effect of promoting proliferation, which may be related to the regulatory effect of SERMs on estrogen receptor. It is speculated that SERMs can express estrogen receptor inhibitors in uterine leiomyoma. Even when estrogen was added, the receptors were inhibited, and estrogen can not play a role, which eventually leads to blocked cell proliferation. Other studies have shown that SERMs have a strong inhibitory effect on ER-alpha, but only a weak inhibitory effect on ER-beta (27). In this experiment, estrogen in the TSEC group might induce the growth of leiomyoma cells through interaction with ERbeta. However, quantitative expression of specific receptors requires further study. There was significant difference in the expression of PCNA between the $\mathrm{E}$ and blank control group, reflecting the estrogen dependence of leiomyoma cells. Although TSEC cannot completely inhibit the proliferation of leiomyoma cells, it is similar to the blank control, which provides a basis for the safety of raloxifene combined with 17-beta estradiol. While uterine leiomyoma is estrogen dependent, in the presence of estrogen, TSEC may have better safety for perimenopausal patients with leiomyoma.

Bcl-2 belongs to the apoptosis suppressor gene. Its high expression indicates that the apoptosis ability is weakened. Palomba et al. showed that SERMs could promote the apoptosis of uterine leiomyoma cells compared with the control group (25). Jin et al. showed that SERMs had no significant effect on apoptosis compared with the control group (37). This study showed that SERMs combined with 17-beta estradiol had lower apoptosis than the $\mathrm{E}+\mathrm{P}$ and $\mathrm{E}$ group. That might be related to the concentration of raloxifene used in this experiment. Palomba et al.'s experiments showed that SERMs could reduce the volume of leiomyoma by inhibiting proliferation and promoting apoptosis (38). It has been suggested that SERMs can promote apoptosis, but the effect of SERMs on leiomyoma cells is dose-dependent. Low concentration SERMs inhibit the expression of Bcl-2 (37). The concentration of drugs used in this experiment was the cell concentration converted by conventional treatment dose. SERMs combined with 17-beta estradiol had similar apoptosis effect as the blank control group. This may be due to the fact that SERMs can only inhibit the expression of estrogen receptor, while uterine leiomyomas are estrogen- and progesteronedependent tumors, and progesterone may have a greater impact on the volume of leiomyomas. Inhibition of the expression of estrogen receptor alone does not completely inhibit the mitosis of leiomyoma cells, resulting in the effect that leiomyomas do not grow but also cannot reduce. In view of the fact that uterine leiomyoma is an estrogen-dependent tumor, progesterone can promote the proliferation of leiomyoma cells, while SERMs can promote apoptosis, so TSEC may have better safety than $\mathrm{E}+\mathrm{P}$ or $\mathrm{E}$ alone for perimenopausal patients with leiomyoma.

There are some shortcomings in this experiment. The expression of ER-alpha and ER-beta in leiomyoma cells was not quantitatively analyzed after drug treatment, to intuitively understand the imbalance of estrogen receptor expression in the pathogenesis of uterine leiomyoma, which provides guidelines for follow-up drug intervention. No concentration gradient test was conducted to determine whether SERMs inhibited estrogen receptors in a concentration-dependent manner, and the minimum 
effective concentration of the drug could not be determined.

In further research, we plan to study the effect of TSEC on the expression of estrogen receptor to understand the mechanism of TSEC on uterine leiomyoma cells and whether it can reduce cell proliferation through competitive inhibition of receptors or regulate the coupling protein GPR30 downstream of estrogen receptor. In addition, we will design the concentration gradient test of the two drugs in TSEC, continue to find the lowest effective dose, and further improve the safety of the drug on the premise of effectiveness.

Compared with estrogen and progesterone or estrogen alone, SERM combined with estrogen may have better safety in MHT of perimenopausal women with uterine leiomyoma.

\section{Acknowledgments}

The authors thank Prof. Enqi Liu from the Laboratory Animal Center of Xi' an Jiaotong University School of Medicine for helping with the laboratory work.

Funding: The authors disclosed receipt of the following financial support for the research, authorship, and/or publication of this article: This work was supported by the Science and Technology Research and Development Program of Shaanxi Province (S2015YFSF0280), Key Research and Development Project of Shaanxi Provincial Science and Technology Department (2017ZDXM-SF-068), Natural Foundation of Shaanxi Province (2017ZDJC-11), and Shaanxi Provincial Collaborative Technology Innovation Project (2017XT-026, 2018XT-002).

\section{Footnote}

Data Sharing Statement: Available at http://dx.doi. org/10.21037/tcr-19-3022a

Conflicts of Interest: All authors have completed the ICMJE uniform disclosure form (available at http://dx.doi. org/10.21037/tcr-19-3022a). The authors have no conflicts of interest to declare.

Ethical Statement: The authors are accountable for all aspects of the work in ensuring that questions related to the accuracy or integrity of any part of the work are appropriately investigated and resolved. The study was conducted in accordance with the Declaration of Helsinki (as revised in 2013). The study was approved by the Ethics
Committee of the First Affiliated Hospital of Xi'an Jiaotong University (No. XJTU1AF2016LSK-14: the registration number of ethics board). The patient's permission and signed informed consent were obtained before operation.

Open Access Statement: This is an Open Access article distributed in accordance with the Creative Commons Attribution-NonCommercial-NoDerivs 4.0 International License (CC BY-NC-ND 4.0), which permits the noncommercial replication and distribution of the article with the strict proviso that no changes or edits are made and the original work is properly cited (including links to both the formal publication through the relevant DOI and the license). See: https://creativecommons.org/licenses/by-nc-nd/4.0/.

\section{References}

1. Thompson JD. TeLinde's Operative Gynecology. Ann Surg 1992;191:126.

2. Gregoriou $\mathrm{O}$, Konidaris S, Botsis D, et al. Long term effects of Tibolone on postmenopausal women with uterine myomas. Maturitas 2001;40:95-9.

3. Farris $\mathrm{M}$, Bastianelli $\mathrm{C}$, Rosato $\mathrm{E}$, et al. Uterine fibroids: an update on current and emerging medical treatment options. Ther Clin Risk Manag 2019;15:157-78.

4. Kwak EK, Park HS, Kang NM. Menopause Knowledge, Attitude, Symptom and Management among Midlife Employed Women. J Menopausal Med 2014;20:118-25.

5. Santen RJ, Allred DC, Ardoin SP, et al. Postmenopausal hormone therapy: an Endocrine Society scientific statement. J Clin Endocrinol Metab 2010;95:s1-s66.

6. Stuenkel CA, Davis SR, Gompel A, et al. Treatment of Symptoms of the Menopause: An Endocrine Society Clinical Practice Guideline. J Clin Endocrinol Metab 2015;100:3975-4011.

7. Colacurci N, De Franciscis P, Cobellis L, et al. Effects of hormone replacement therapy on postmenopausal uterine myoma. Maturitas 2000;35:167-73.

8. Polatti F, Viazzo F, Colleoni R, et al. Uterine myoma in postmenopause: a comparison between two therapeutic schedules of HRT. Maturitas 2000;37:27-32.

9. Simsek T, Karakus C, Trak B. Impact of different hormone replacement therapy regimens on the size of myoma uteri in postmenopausal period: tibolone versus transdermal hormonal replacement system. Maturitas 2002;42:243-6.

10. Sommer EM, Balkwill A, Reeves G, et al. Effects of obesity and hormone therapy on surgically-confirmed fibroids in postmenopausal women. Eur J Epidemiol 2015;30:493-9. 
11. Šmejkal M, Ricard D, Prchalová M, et al. Biomass and abundance biases in European standard gillnet sampling. PLoS One 2015;10:e122437.

12. McDonnell DP. The Molecular Pharmacology of SERMs. Trends Endocrinol Metab 1999;10:301-11.

13. Liu J, Matsuo H, Xu Q, et al. Concentration-dependent effects of a selective estrogen receptor modulator raloxifene on proliferation and apoptosis in human uterine leiomyoma cells cultured in vitro. Hum Reprod 2007;22:1253-9.

14. Bolognese MA. SERMs and SERMs with estrogen for postmenopausal osteoporosis. Rev Endocr Metab Disord 2010;11:253-9.

15. Mirkin S, Pickar JH. The Tissue-Selective Estrogen Complex (TSEC): A Promising New Therapy for Menopausal Symptoms and Postmenopausal Osteoporosis. Curr Obstet Gynecol Rep 2012;1:50-8.

16. Komm BS, Mirkin S, Jenkins SN. Development of conjugated estrogens/bazedoxifene, the first tissue selective estrogen complex (TSEC) for management of menopausal hot flashes and postmenopausal bone loss. Steroids 2014;90:71-81.

17. Mirkin S, Komm BS, Pan K, et al. Effects of bazedoxifene/ conjugated estrogens on endometrial safety and bone in postmenopausal women. Climacteric 2013;16:338-46.

18. Carneiro AL, de Cassia de Maio Dardes R, Haidar MA. Estrogens plus raloxifene on endometrial safety and menopausal symptoms--semisystematic review. Menopause 2012;19:830-4.

19. Carranza-Lira S, Gooch AL, Saldivar N, et al. Climacteric symptom control after the addition of low-dose esterified conjugated estrogens to raloxifene standard doses. Int J Fertil Womens Med 2007;52:93-6.

20. Pinkerton JV, Shifren JL, La Valleur J, et al. Influence of raloxifene on the efficacy of an estradiol-releasing ring for treating vaginal atrophy in postmenopausal women. Menopause 2003;10:45-52.

21. Valiati B, Capp E, Edelweiss MI, et al. Effect of raloxifene and low-dose percutaneous 17beta-estradiol on menopause symptoms and endometrium--a randomized controlled trial. Maturitas 2009;62:81-4.

22. Stovall DW, Utian WH, Gass ML, et al. The effects of combined raloxifene and oral estrogen on vasomotor symptoms and endometrial safety. Menopause 2007;14:510-7.

23. Davis SR, O'Neill SM, Eden J, et al. Transition from estrogen therapy to raloxifene in postmenopausal women: effects on treatment satisfaction and the endometrium-a pilot study. Menopause 2004;11:167-75.

24. Jirecek S, Lee A, Pavo I, et al. Raloxifene prevents the growth of uterine leiomyomas in premenopausal women. Fertil Steril 2004;81:132-6.

25. Palomba S, Orio F Jr, Morelli M, et al. Raloxifene administration in premenopausal women with uterine leiomyomas: a pilot study. J Clin Endocrinol Metab 2002;87:3603-8.

26. Palomba S, Sammartino A, Di Carlo C, et al. Effects of raloxifene treatment on uterine leiomyomas in postmenopausal women. Fertil Steril 2001;76:38-43.

27. Deng L, Wu T, Chen XY, et al. Selective estrogen receptor modulators (SERMs) for uterine leiomyomas. Cochrane Database Syst Rev 2012;10:CD005287.

28. Zandvakili F, Seyedoshohadaie F, Rezaiee M, et al. Comparison of the effects of gonadotropin-releasing hormone and raloxifeneon the size of uterine leiomyoma. Chronic Diseases Journal 2014;2.

29. Sakr S, Naqvi H, Komm B, et al. Endometriosis impairs bone marrow-derived stem cell recruitment to the uterus whereas bazedoxifene treatment leads to endometriosis regression and improved uterine stem cell engraftment. Endocrinology 2014;155:1489-97.

30. Chung YJ, Chae B, Kwak SH, et al. Comparison of the inhibitory effect of gonadotropin releasing hormone $(\mathrm{GnRH})$ agonist, selective estrogen receptor modulator (SERM), antiprogesterone on myoma cell proliferation in vitro. Int J Med Sci 2014;11:276-81.

31. Mirkin S, Komm BS. Tissue-selective estrogen complexes for postmenopausal women. Maturitas 2013;76:213-20.

32. Carranza LS. Relation between hormonal therapy and tibolone with SERMs in postmenopausal women's myomes growth. Ginecol Obstet Mex 2008;76:610-4.

33. Kim HT, Kim BC, Kim IY, et al. Raloxifene, a mixed estrogen agonist/antagonist, induces apoptosis through cleavage of BAD in TSU-PR1 human cancer cells. J Biol Chem 2002;277:32510-5.

34. Palomba S, Orio F Jr, Russo T, et al. Antiproliferative and proapoptotic effects of raloxifene on uterine leiomyomas in postmenopausal women. Fertil Steril 2005;84:154-61.

35. Lingxia $X$, Taixiang $W$, Xiaoyan C. Selective estrogen receptor modulators (SERMs) for uterine leiomyomas. Cochrane Database Syst Rev 2007;(2):CD005287.

36. Kim JJ, Sefton EC. The role of progesterone signaling in the pathogenesis of uterine leiomyoma. Mol Cell Endocrinol 2012;358:223-31.

37. Jin L, Sugiyama H, Takigawa M, et al. Comparative studies of anthraquinone- and anthracene-tetraamines as blockers 
of N-methyl-D-aspartate receptors. J Pharmacol Exp Ther 2007;320:47-55.

38. Palomba S, Orio F Jr, Morelli M, et al. Raloxifene administration in women treated with gonadotropin-

Cite this article as: Lv SL, Wang R, Xue X, Zhao LB, Tuo XQ, Ma SJ, Liang DX, Wang YR, Feng X, Li Q, Wang Q, Han L, Li QL. Selective estrogen receptor modulator with estrogen does not affect the proliferation and apoptosis of uterine leiomyoma cells. Transl Cancer Res 2020;9(9):5390-5400. doi: $10.21037 /$ tcr-19-3022a releasing hormone agonist for uterine leiomyomas: effects on bone metabolism. J Clin Endocrinol Metab 2002;87:4476-81. 